\title{
Aprendizado na modalidade interprofissional: a voz de estudantes de programa de residência em saúde
}

\author{
Sonia Maria Dias
}

\section{Resumo}

Introdução $\mathrm{Na}$ intenção de adotar estratégia de ensino tendo por base o conceito de educação interprofissional da OMS - Organização Mundial de Saúde (2010), um grupo de professores passou a delinear conteúdo curricular do programa de residência Integrada Multiprofissional em Atenção Hospitalar desenvolvido a partir do ano de 2015 na Universidade Federal de Juiz de Fora - MG. Buscou-se então, a desenhar a estrutura de ensino alinhada ao conceito da OMS, de modo a permitir as profissões aprenderem sobre e com os outros e entre si por meio do trabalho em equipe de forma colaborativa, visando elevar a qualidade de ações em saúde. Nesse sentido a OMS (2010) destaca a importância de órgãos formadores de profissionais adotarem políticas de educação integradas, para as diferentes profissões aprenderem a trabalhar junto a usuários, famílias, cuidadores e comunidade, ancorados no trabalho em equipe visando à prática colaborativa para a melhoria de resultados do complexo trabalho no sistema de saúde. Diante da relevância da educação interprofissional este estudo tomou por objeto de investigação, a vivência do estudante acerca do aprendizado interprofissional proposto pelo ensino inserido no programa de residência Integrada Multiprofissional em Atenção Hospitalar. Objetivo Relatar o significado expressado por residentes da vivência de aprendizagem interprofissional. Método Natureza do estudo: Este estudo optou-se por investigação exploratória, descritiva com abordagem qualitativa sob a luz das representações sociais. Cenário da pesquisa: $\mathrm{O}$ cenário da pesquisa foi em uma unidade acadêmica da Universidade Federal de Juiz de Fora - MG. Participantes da pesquisa: Os participantes foram 19 estudantes que estavam cursando o programa de residência, no período de 2015 a 2017, sendo este, o primeiro programa em desenvolvimento no cenário desta pesquisa que abraçava profissionais de diferentes áreas do campo da saúde: serviço social, enfermagem, farmácia, fisioterapia, nutrição e psicologia. Os esclarecimentos quanto a natureza da pesquisa, os objetivo, os método, os riscos e os benefícios previstos, ocorreram durante as atividades desenvolvidas da disciplina Seminário Integrador, que posteriormente recebeu a alteração de nome para Seminário Interprofissional em Atenção Hospitalar. Essa disciplina foi planejada para o ensino e aprendizagem em sala de aula, com conteúdos originados das vivências do campo de prática enriquecidos pelas discussões de temas, casos clínicos e de processo de trabalho com enfoque interprofissional e prática colaborativa. Coleta e tratamento de informações: A coleta de informações ocorreu em dezembro de 2016 a fevereiro de 2017, foi realizada através de instrumento de questionário, que não solicitou identificação dos participantes para possibilitar plena liberdade de expressão às respostas. Para o tratamento foi utilizada a técnica de análise de comunicações de Bardin (2011), que permite categorizar as informações por suas características comuns sob um título genérico. A pesquisa recebeu parecer de aprovação do comitê de ética de pesquisa em seres humanos número 1.049.234/2015. Resultados Antes de apresentar os resultados obtidos nesta pesquisa cabe esclarecer que, os integrantes do núcleo docente assistencial estruturante que abraçaram o programa de residência, davam início a nova vivência pedagógica de caráter interprofissional. Merece ressaltar que o corpo docente buscou estratégias de aprendizado para si, como forma de compreender o campo da educação interprofissional. Para ilustrar, citam-se algumas dessas estratégias: leituras e discussões de textos; organização de seminários; participação de cursos de iniciativas do governo federal sendo um deles, Desenvolvimento da Competência Docente para Educação Interprofissional em Saúde e o outro intitulado de Apoio aos Programas de Residência em Área Profissional da Saúde. Foram também incluídas nas estratégias de aprendizado do corpo docente, a participação do evento I Colóquio 
ISSN 2179-6750

Internacional de Educação e Trabalho Interprofissional em Saúde ocorrido em 2015 e a participação de reuniões ordinárias de grupo de pesquisas e a constante trocas de conhecimentos entre os membros docentes. Para o professor ser facilitador e a educação interprofissional acontecer, pode ser algo desafiador, pois exige-se habilidades, entendimento de dinâmicas de grupo, criatividade para lidar com as diversidades, entre outros necessários requisitos. Referente às respostas obtidas dos participantes desta pesquisa, ficou evidente que, o ensino e aprendizagem na forma de ordenar a ação política para a intervenção em saúde na modalidade interprofissional visando à prática colaborativa, era também vivência nova por todos os participantes. As respostas acerca do significado da vivência de aprendizagem interprofissional, permitiram construir duas categorias de análise. A primeira categoria de significados foi denominada de vantagens da aprendizagem interprofissional e a segunda categoria reuniu as estratégias para o aprimoramento da aprendizagem. Categoria 1: Vantagens da aprendizagem interprofissional As respostas revelavam ideias relacionadas à vantagem de visualizar a competência, no tocante ao marco regulatório de cada profissão. Termos expressados como "fica claro funções desempenhados de cada profissão", "prestar cuidado humanizado, sedimentando a integralidade", "facilidade de sanar dúvidas relacionadas ao cuidado". As resposta colocadas permitiram também observar a preocupação com a temática de segurança do paciente quando relataram, "melhora da comunicação entre profissionais", "compreensão do estado clínico do usuário", "assistência segura devido a prática colaborativa", "possibilidade de atendimento ampliado do cuidado com diversas áreas profissionais, incluindo o usuário e familiar", foram resposta marcantes. Categoria 2: Estratégias para o aprimoramento da aprendizagem interprofissional Entre as estratégias elencadas, uma delas dizia respeito à manutenção de atividades programadas pela disciplina Seminário Interprofissional em Atenção Hospitalar como, "as discussões de casos clínicos e de processos de trabalho com enfoque colaborativo". Outras estratégias indicadas pelos participantes referiam-se a fatores organizacionais como, "investimento na qualidade e no quantitativo de preceptores", pois os participantes sentiam lacunas na sua formação decorrente da ausência do ensino realizado pelo preceptor do serviço hospitalar. No que diz respeito à deficiência da preceptoria, esse fato teve por significado, o comprometimento da segurança sentida por parte de participantes, para o enfrentamento de situações sobretudo as de natureza percebida como conflituosas. Outras estratégias colocadas referiam-se a necessidade de "política de implantação para a alta compartilhada" e "adoção da cultura de trabalho na forma de linha de cuidado". Considerando-se que o ser humano é criatura social, fato observado desde os primórdios da história da cultura da antiguidade, isso traz como significado que, a companhia uns dos outros na convivência coletiva, pode resultar desempenho de tarefas e ações compartilhadas para acelerarem ciclos dos processos do cotidiano. Portanto, as pessoas agrupam-se como necessária forma de interação para práticas no trabalho em saúde e na convivência social. Conclusão Ficou evidente que a mobilização do conjunto de práticas em saúde possibilita contemplar a perspectiva da aprendizagem interprofissional, considerando-se o interesse do trabalho em conjunto. Houve o entendimento de que é necessário ocorrer a articulação de saberes e práticas, dar realce ao trabalho em equipe com enfoque à colaboração para resultar em aprendizagem interprofissional.

Descritores: Educação de pós-graduação, Aprendizagem, Comportamento cooperativo, Equipe de assistência ao paciente 